International Journal of Scientific Innovations. Vol. 1(02), pp 006-014, Dec, 2017

Available online at http://www.ijsionline.com

DOI: 10.32594/IJSI_20180102

ISSN 2631-3529

\title{
Optimization of sensory properties of chemically preserved Mushrooms through response surface methodology
}

\author{
Sarfraz Hussain ${ }^{1 *}$, Salim-ur-Rehman ${ }^{2}$, Qaisar Raza ${ }^{3}$, Itrat Fatima ${ }^{1}$, Syeda Mahvish Zahra ${ }^{1}$, Farhat Rashid ${ }^{1}$, and Ayesha Rafique ${ }^{1}$ \\ ${ }^{1}$ Department of food Science \& Nutrition, University of Sargodha, Sargodha, Pakistan. \\ ${ }^{2}$ National Institute of Food Science \& Technology, University of Agriculture, Faisalabad, Pakistan. \\ ${ }^{3}$ Department of Health Sciences, Vrije Universiteit, De Boelelaan 1085, Kamer O-534, 1081 HV Amsterdam, the Netherlands.
}

\begin{tabular}{|c|c|}
\hline ARTICLE INFO & ABSTRACT \\
\hline $\begin{array}{l}\text { Received on: } 29 / 11 / 2017 \\
\text { Accepted on: 10/12/2017 } \\
\text { Available online: } 31 / 12 / 2017 \\
\text { Key words: } \\
\text { Mushrooms, preservation, } \\
\text { response surface } \\
\text { methodology, sensory } \\
\text { properties }\end{array}$ & $\begin{array}{l}\text { In developing countries, lack of functional storage facilities, inadequacy of transportation and communication gap } \\
\text { increases the necessity of using certain chemical additives for the purpose of food preservation due to their cheapness. In } \\
\text { such circumstances, food additives can be used to supplement the effectiveness of traditional methods of food } \\
\text { preservation rather than to replace them. Response surface methodology was applied to find out the optimum levels of } \\
\text { potassium metabisulphite and sodium benzoate and their response on sensory characters. The values of } 7.30 \text { for } \\
\text { Agaricusbisporus, } 6.31 \text { for Agaricusbitorquis and } 7.4 \text { for Pleurotusostreatus reflected the optimum levels of score for } \\
\text { color and } 7.50 \text { for A. bisporus, A. bitorquis and P. ostreatus for flavor and optimum value of } 7.15 \text { for A. bisporus, } 7.40 \\
\text { for A. bitorquis and P.ostreatus for taste were obtained when citric acid } 2 \% \text {, acetic acid } 0.3 \% \text {, sodium chloride } 5 \% \text {, } \\
\text { ascorbic acid } 0.01 \% \text {, potassium sorbate } 0.1 \% \text {, potassium metabisulphite and sodium sorbate } 0.075 \% \text { were used for } \\
\text { preservation. An effective combination of chemical preservatives was developed for long term storage of three } \\
\text { mushrooms in steeping solution. A minimum dose of } 0.075 \% \text { potassium Meta bisulfite and sodium benzoate was found } \\
\text { to be effective against browning without adversely effecting sensory properties during storage of } 90 \text { days. }\end{array}$ \\
\hline
\end{tabular}

\section{INTRODUCTION}

Desirability of a food product is not necessarily correlated with its nutritional value. But there are other factors as appearance, taste and aroma which also stimulate the appetite and determine the preference of certain foods. Thus, in addition to nutritional value, edible mushrooms possess unique characteristics in terms of aroma, color, flavor and texture, which make them attractive for human consumption [1]. It is postulated that taste buds play vital role in selection of certain foods which latter on become balanced diet of that individual. Similarly, there are clear cut understandings that four different blood groups have variable taste buds which are primary motives for selection of certain foods having a specific taste food. Mushrooms are having blood pressure lowering quality and other proven health effects [2]. Greek medicine practitioners designate white color foods as cold foods which are tasteless and produce phlegm in the body. Blood group "A" is designated as phlegmatic and should avoid such foods [3].

*Corresponding Author

Sarfraz Hussain, Department of food Science \& Nutrition, University of Sargodha, Sargodha, Pakistan.

E-mail: sarfrazuaf2002@yahoo.co.uk
This is particularly important to know about its potential effect on body when consumed after processing and preservation. Flavoring systems are of vital importance in savory food manufacturing. Food industries are producing foods which are particularly attractive to potential Consumers because of their typical flavors. Consequently, food industry dealing with these products is showing great interest in the use of food ingredient scurrying the umami taste and flavor enhancement systems [4]. Certain kinds of mushrooms are considered as delicacy throughout the world. However, flavor qualities of mushrooms are greatly dependent on the numerous volatile and semi-volatile compounds contained within the mushroom complex [5]. From the quality point of view, mushrooms have to be processed immediately after harvesting. Among the methods of food preservation, canning, dehydration, freezing, pickling and steeping are widely accepted methods for long term preservation. But the prices of canned and frozen products are exorbitant and ultimately a few people may afford to purchase such products. Steeping preservation of mushrooms might be a convenient and economical method for the extension of shelf-life and to transport this highly perishable commodity to outlying and remote places for further processing as canning and product manufacturing. Information on standard methods of mushroom preservation with minimum dozes of chemical additives in steeping solution for a long term is quite scanty [6].

@@®® (2018 Sarfraz Hussain et al. This is an open access article distributed under the terms of the Creative Commons Attribution Licenses NonCommercialShareAlikeUnported License (http://creativecommons.org/licenses/by-nc-sa/4.0/). 
The response surface model permits us to determine optimal conditions for process or level of individual parameters (may be a combination of chemical preservatives) required to reach a particular response level [7]. Sensory characteristics optimized by RSM were found beneficial for the development of shelf stable mushroom product [8]. The food industry is taking interest in qualitative and quantitative attributes by developing relationship between analytical measurements and sensory responses by comparing two sets of multivariate data [9]. As a result, consumer's preferences are correlated with product attributes through sensory acceptability, consumer testing and analyzing the data through complex statistical procedures. Food technologists have used multivariate statistical techniques to reach a better understanding of food characteristics. This project was designed to preserve locally grown mushrooms with minimum doses of chemical preservatives and to evaluate for acceptability through sensory analysis.

\section{MATERIALS AND METHODS}

\section{Procurement of raw materials}

Commercially available, freshly harvested button (Agaricus bitorquis and Agaricus bisporus) and oyster mushrooms (Pleurotus ostreatus) grown on cotton waste were procured from commercial mushroom farms located at Sheikhupura and Faisalabad. The culture of A. bitorquis (AGS W 20) was originally obtained from HRI wells Bourne, U.K. and revived at the culture bank of Institute of Horticultural Sciences, Mushroom Research Laboratory, University of Agriculture, Faisalabad, Pakistan and the research was conducted in the fruit and vegetables research laboratory.
National Institute of Food Science and Technology, University of Agriculture, Faisalabad, Pakistan. Other materials such as acetic acid, ascorbic acid, potassium sorbate and citric acid, potassium met bisulfite (KMS), sodium benzoate (SB) and sodium chloride were purchased from local scientific stores.

\section{Method of Mushroom preservation}

To avoid rapid browning of mushrooms during preparation and washing, the mushrooms were cut with blade knife into $2-3 \mathrm{~mm}$ thick slices and washed in the solution containing $0.1 \%$ citric acid and $0.3 \%$ KMS. The mushroom slices were blanched in boiling water for 4 minutes to inactivate enzymes and cooled with potable water to avoid further nutrient and flavor losses [10].

\section{Preparation of steeping solution for chemical preservation}

Steeping solution was prepared by dissolving calculated doses of chemicals to keep their concentration constant throughout the study period by using the formula as stated by Bennet [11]. The steeping solution contained table salt $5 \%$, acetic acid $0.3 \%$, ascorbic acid $0.1 \%$, potassium sorbate $0.1 \%$ Citric acid (2 - 4 $\%$ ) was used to adjust the $\mathrm{pH}$ of Steeping solution to 4.0 using a ph. meter (Hanna model-8520, Italy) (Table 2). The doses of above chemicals were kept constant, while, KMS and SB were used in the steeping solution as independent variables according to the models generated by Response Surface Methodology [12 and 13], presented in Tables 1-3.

Table 1. Coded and original levels of independent variables

\begin{tabular}{|c|c|c|c|c|c|}
\hline \multirow{2}{*}{ Original levels } & \multicolumn{5}{|c|}{ Coded scale } \\
\cline { 2 - 6 } & -2 & -1 & 0 & 1 & 2 \\
\hline KMS (A) & $0.05 \%$ & $0.06 \%$ & $0.07 \%$ & $0.08 \%$ & $0.09 \%$ \\
\hline SB (B) & $0.05 \%$ & $0.06 \%$ & $0.07 \%$ & $0.08 \%$ & $0.09 \%$ \\
\hline
\end{tabular}

\begin{tabular}{|c|c|}
\hline Independent Variables: & Dependent Variables: \\
\hline 1) Potassium meta bisulfite $(\mathrm{X})$ & 1). Color $(\mathrm{Y})$ \\
\hline 2) Sodium benzoate $(\mathrm{X})$ & 2). Flavor $(\mathrm{Y})$ \\
\hline & 3). Taste (Y) \\
\hline
\end{tabular}

Table 2. Work Plan of chemical treatments for preservation of mushrooms

\begin{tabular}{|c|c|c|}
\hline Oyster Mushroom & \multicolumn{2}{|c|}{ Button Mushrooms } \\
\hline P. ostreatus & A. bisporus & A. bitorquis \\
\hline $\begin{array}{c}\text { Constant values: Citric acid 2-4 \%, Acetic acid 0.3\%, } \\
\text { sodium chloride 5 \%, Ascorbic acid } 0.1 \%, \text { Potassium } \\
\text { sorbate } 0.1 \% .\end{array}$ & $\begin{array}{c}\text { Constant values: Citric acid 2-4 \%, Acetic } \\
\text { acid } 0.3 \%, \text { sodium chloride } 5 \%, \text { Ascorbic } \\
\text { acid } 0.1 \%, \text { Potassium sorbate } 0.1 \% .\end{array}$ & $\begin{array}{c}\text { Constant values: Citric acid 2-4 } \%, \text { Acetic } \\
\text { acid } 0.1 \%, \text {, sodium chloride } 5 \%, \text { Ascorbic } \\
\text { acium sorbate } 0.1 \% .\end{array}$ \\
\hline
\end{tabular}


Table 3. Design Matrix for Two Factors with Blocks for Fitting Second-Order Response Model

\begin{tabular}{|c|c|c|}
\hline Block & KMS & SB \\
\hline \multirow{4}{*}{ Block-1 } & -1 & -1 \\
\cline { 2 - 3 } & -1 & 1 \\
\cline { 2 - 3 } & 1 & -1 \\
\cline { 2 - 3 } & 1 & 1 \\
\cline { 2 - 3 } & 0 & 0 \\
\cline { 2 - 3 } & 0 & 0 \\
\hline \multirow{5}{*}{ Block-2 } & 0 & 0 \\
\cline { 2 - 3 } & 0 & 0 \\
\cline { 2 - 3 } & 0 & -2 \\
\cline { 2 - 3 } & 0 & 2 \\
\cline { 2 - 3 } & -2 & 0 \\
\cline { 2 - 3 } & 2 & 0 \\
\cline { 2 - 3 } & 0 & 0 \\
\cline { 2 - 3 } & 0 & 0 \\
\hline
\end{tabular}

\section{Method of packing of Mushrooms}

The mushrooms were packed in pre-warmed glass jars having $300 \mathrm{~mL}$ capacity with steeping solution in equal quantity of mushrooms and steeping solution at filling temperatures ranging from 90 to $95{ }^{\circ} \mathrm{C}$. The temperature of steeping solution in glass jars was measured as close as possible to the geometric center of the jar [14]. The caps of glass jars were internally lined with aluminum foil to avoid any reaction between steeping solution and lid of the jar. The glass jars were cooled in air to give an extra safety margin to avoid breakage and the containers were inverted and put in a horizontal position at least for 5 minutes. Samples were stored at ambient temperature $\left(27-30^{\circ} \mathrm{C}\right)$ for further analyses.

\section{Sensory Evaluation}

Sensory evaluation of chemically preserved mushrooms was conducted to judge their quality on the basis of color, flavor and taste by a panel of 20 judges to assess consumer's acceptability on 9-point Hedonic Scale at the end of the study period after 90 days' storage period [15]. Response surface technique was applied to find out the optimum levels of KMS and SB and their responses on sensory characters.

\section{Statistical Analyses}

Data were analyzed by using Analysis of Variance and Response Surface Techniques [13,16 and 17]

\section{RESULTS AND DISCUSSION}

\section{Color}

Color of food products significantly influences the acceptance of products by consumer. It affects our overall judgment, quality and used as a strong indicator of product aesthetics, safety and value. Use of mushrooms as health foods also depends on colors. Similarly, results may vary considerably due to human differences in color perception and error. Preserved mushrooms were offered for evaluation of color visually at the end of study period to evaluate their acceptability and fresh mushrooms were kept as reference for comparison. The contour diagrams (Figure 1-3) show maximum responses for color at optimum levels of chemical preservatives KMS and SB for preservation of A. bisporus, $A$. bitorquis and $P$. ostreatus mushrooms. 0.073 and 0.067 , and 0.074 and 0.067 for KMS and SB, respectively) against the central point of the contours were fitted in the equation (Figure 1-3), a value of 7.30 for A. bisporus, 6.31 for A. bitorquis and 7.4 for $P$. ostreatus were obtained which reflected the optimum levels of score for color obtained as a result of combination of chemical preservatives. The signs of the regression coefficients within each equation show the direction of the effect of each independent variable, the squares and the interaction. Considering such information together with the $\mathrm{F}$ values (Table 4) provided insight.

The regression analyses of data on sensory evaluation based on score assigned by judges for color to A. bitorquis and $P$. ostreatus show a significant effect of KMS, while A. bisporus show non-significant results. Similarly, all three mushrooms showed significant results for SB. Similarly, results for X12 for all three mushrooms are highly significant. Regression analyses for X22 show highly significant $(\mathrm{P}<0.01)$ values for $A$. bisporus and $P$. ostreatus mushrooms. However, A. bitorquis has significant value for X22. Results for interaction between $\mathrm{X} 1$ and $\mathrm{X} 2$ for all three mushrooms are non-significant.

Mean square values for regression analyses (Table 4) for A. bisporus show highly significant $(\mathrm{P}<0.01)$ difference, while A. bitorquis and P. ostreatus show significant results $(\mathrm{P}<0.05)$. The higher $\mathrm{R} 2$ values more than $50 \%$ and near to $100 \%$ shows good fit of the model. The values for A. bisporus (81.1\%), A. bitorquis $(70.0 \%)$ and P. ostreatus $(75.2 \%)$ also show adequate fit of the data and good fit of the models. Color is one of the most important parameters perceived by the human eye and is correlated with other quality attributes. Perception of color can be influenced by quality, quantity, type and intensity of available light, chemical and physical characteristics of the commodity, and the ability of judges to characterize color [18].

Scientific studies are mainly aimed at to keep the original color of the mushrooms during the period of post-harvest handling, processing and distribution [19]. The color changes from white to brown are also evident during prolonged storage due to the activities of polyphenol oxidase (PPO), and monophenol mono-oxidase (tyrosinase) enzymes [20 and 21]. Browning reactions become evident when mushrooms are subjected to processing [22]. In present studies, mushrooms were selected at the same phase of maturity from same flushes because, mushrooms from successive flushes become progressively darker prior to harvesting and browning occurs at a faster rate during postharvest storage [23]. The browning tendency between breaks is also affected by differences in composition, susceptibility to injury due to environmental conditions or crop density, and extraction of PPO from mushroom surface during washing [24]. The mushrooms were blanched in boiling water in order to inactivate the enzyme system and to expel the air from the cell of the mushrooms because most important factors that determine the rate of enzymatic browning in mushrooms are the concentration of active PPO and phenolic compounds present, the $\mathrm{pH}$, the temperature and the oxygen availability to the tissue. Lascorbic acid was used in processing of mushrooms as an oxygen scavenger [25 and 26]. The temperature stability of PPO varies with species and cultivars. The enzyme is relatively heat labile and activity is completely destroyed at $80{ }^{\circ} \mathrm{C}$ [27]. These results corroborate with the findings of anonymous [28, 30 and 31]. Who stated that use of $0.05 \%$ and $0.2 \%$ KMS significantly improved the whiteness of mushrooms during storage. 
$z=-6.811+188.774 * x+221.274 * y-1735.294 * x * x+750 * x * y-1985.294 * y * y$

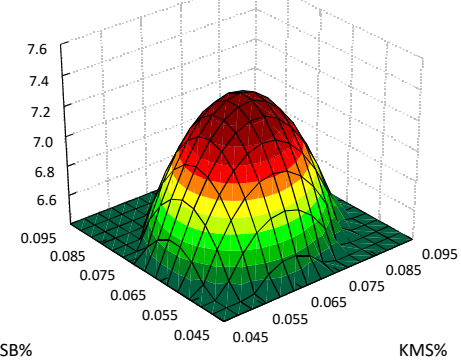

Figure 1. Contour plot showing the effect of SB\% and KMS\% on color of (Agaricus bisporus) mushroom

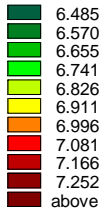

$z=-15.711+361.108 * x+298.441 * y-1810.294 * x * x-1474.999 * x * y-1435.294 * y^{*} y$

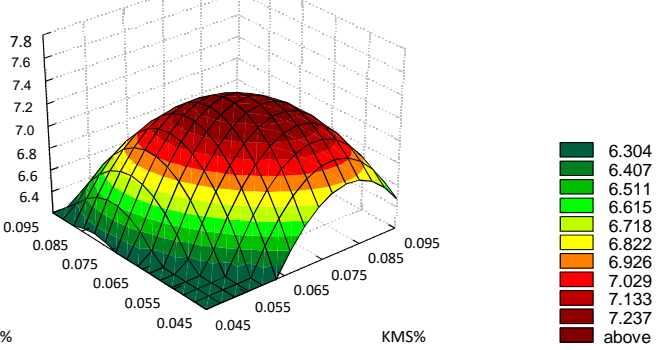

Figure 2. Contour plot showing the effect of SB\% and KMS\% on color of (Agaricus bitorquis) mushroom

$z=-20.791+392.328^{*} x+408.995^{*} y-2040.441^{*} x^{*} x-1374.999^{*} x^{*} y-2290.44^{*} y^{*} y$

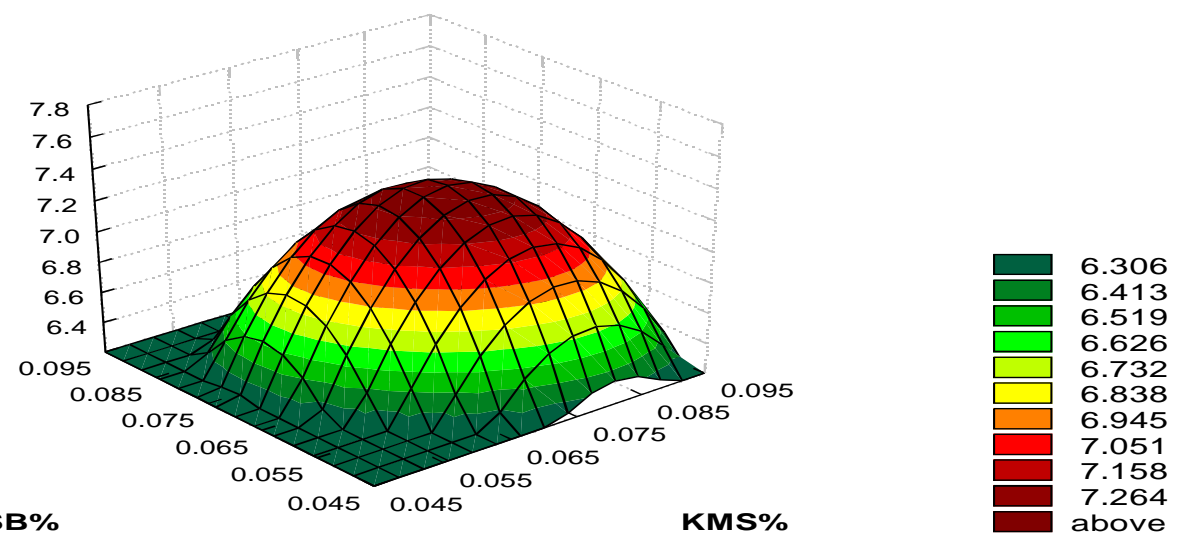

Figure 3. Contour plot showing the effect of SB\% and KMS\% on color of (Pleurotus oystreatus) mushroom

Table 4. Regression Analyses for color of different mushrooms

\begin{tabular}{|c|c|c|c|c|}
\hline \multirow{2}{*}{\multicolumn{2}{|c|}{ Parameter }} & \multicolumn{3}{|c|}{ Regression coefficients } \\
\hline & & A. bisoporus & A. bitorquis & P. ostreatus \\
\hline \multicolumn{2}{|c|}{ Constant } & -6.811 & -15.71 & -20.79 \\
\hline \multicolumn{2}{|c|}{$\mathrm{X}_{1}(\mathrm{KMS} \%)$} & $188.77^{\mathrm{NS}}$ & $361.10 *$ & $392.3 *$ \\
\hline \multicolumn{2}{|c|}{$\mathrm{X}_{2}(\mathrm{SB} \%)$} & $221.27 *$ & $298.40 *$ & $409.0 *$ \\
\hline \multicolumn{2}{|c|}{$\mathrm{X}_{1}^{2}$} & $-1735.30 * *$ & $-1810.30 * *$ & $-2040.4 * *$ \\
\hline \multicolumn{2}{|c|}{$\mathrm{X}_{1} \times \mathrm{X}_{2}$} & $750.00^{\mathrm{NS}}$ & $-1475.00^{\mathrm{NS}}$ & $-1375^{\mathrm{NS}}$ \\
\hline \multicolumn{2}{|c|}{$\mathrm{X}_{2}^{2}$} & $-1985.30 * *$ & $-1435.30 *$ & $-2290.4 * *$ \\
\hline \multicolumn{2}{|c|}{$\mathrm{R}^{2}(\%)$} & 81.1 & 70.0 & 75.2 \\
\hline Source & Degree of freedom & \multicolumn{3}{|c|}{ Mean squares } \\
\hline Regression & 5 & $0.280 * *$ & $0.239 *$ & $0.423 *$ \\
\hline Error & 8 & 0.041 & 0.064 & 0.087 \\
\hline
\end{tabular}




\section{Flavor}

Flavor represents a combination of sensations including taste sweet, salt, sour/acid, bitter/astringent and savory [29], smell, mouth feel and touch which is influenced by storage conditions as temperature influences the volatility of compounds that elicit aroma and odor [32]. In a broader sense flavor may be described as a complex sensation comprising taste, odor, roughness, smoothness, hotness or coldness, and pungency or blandness of food. Flavor of mushrooms is also another important sensory character.
Man derives not only pleasure but satisfaction and security from the flavor of the foods. In the modification of the existing products and development of new products, it is critical that flavor be acceptable to the consumer, for no matter how safe, how nutritious, how inexpensive, or how colorful the food may be, if its flavor is undesirable, it is rejected [33]. The contour diagrams (Figure 4-6) show maximum responses for flavor at optimum levels of chemical preservatives KMS and SB for preservation of A. bisporus, A. bitorquis and P. ostreatus mushrooms

Table 5. Regression Analyses for flavor of different mushrooms

\begin{tabular}{|c|c|c|c|c|}
\hline \multirow{2}{*}{\multicolumn{2}{|c|}{ Parameter }} & \multicolumn{3}{|c|}{ Regression coefficients } \\
\hline & & A. bisoporus & A. bitorquis & P. ostreatus \\
\hline \multicolumn{2}{|c|}{ Constant } & -2.563 & -1.719 & -3.960 \\
\hline \multicolumn{2}{|c|}{$\mathrm{X}_{1}(\mathrm{KMS} \%)$} & $169.46 *$ & $170.27 *$ & $151.76 *$ \\
\hline \multicolumn{2}{|c|}{$\mathrm{X}_{2}(\mathrm{SB} \%)$} & $106.96 *$ & $77.77^{\mathrm{NS}}$ & $177.60 * *$ \\
\hline \multicolumn{2}{|c|}{$\mathrm{X}_{1}^{2}$} & $-1573.5 * *$ & $-1650.7 * *$ & $-1066.2 * *$ \\
\hline \multicolumn{2}{|c|}{$\mathrm{X}_{1} \times \mathrm{X}_{2}$} & $875.0^{\mathrm{NS}}$ & $1000.0^{\mathrm{NS}}$ & $0.0^{\mathrm{NS}}$ \\
\hline \multicolumn{2}{|c|}{$\mathrm{X}_{2}^{2}$} & $-1198.5 * *$ & $-1025.7 *$ & $-1316.2 * *$ \\
\hline \multicolumn{2}{|c|}{$\mathrm{R}^{2}(\%)$} & 89.2 & 83.3 & 87.9 \\
\hline Source & Degree of freedom & \multicolumn{3}{|c|}{ Mean squares } \\
\hline Regression & 5 & $0.186 * *$ & $0.184 * *$ & $0.124 * *$ \\
\hline Error & 8 & 0.014 & 0.023 & 0.011 \\
\hline
\end{tabular}

$z=-2.563+169.461^{*} x+106.961 * y-1573.53 * x^{*} x+875.001 * x^{*} y-1198.529 * y^{*} y$

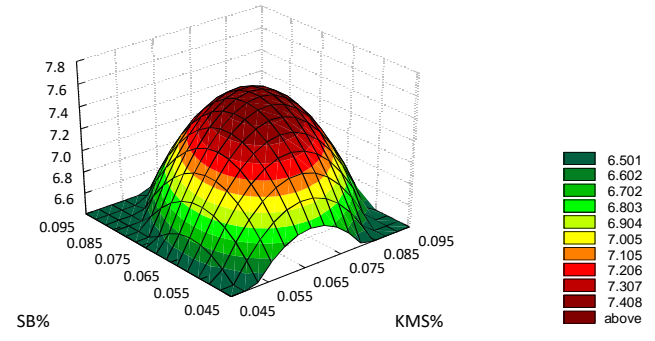

Figure 4. Contour plot showing the effect of KMS\% and SB\% on flavor of (Agaricus bisporus) mushroom $z=-1.719+170.27 * x+77.77 * y-1650.735 * x * x+1000 * x * y-1025.735 * y^{*} y$

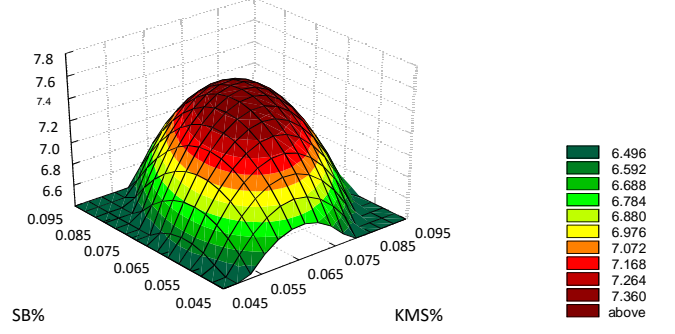

Figure 5. Contour plot showing the effect of KMS\% and SB\% on flavor of (Agaricus bitorquis) mushroom

\section{$z=-5.329+177.794^{*} x+190.294^{*} y-1073.53^{*} x^{*} x-375^{*} x^{*} y-1198.53^{*} y^{*} y$}

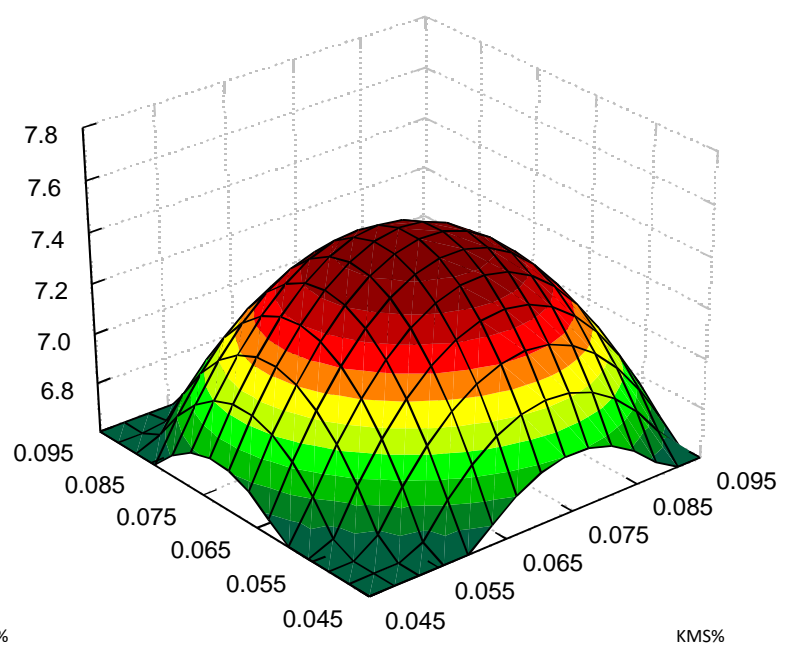


The contours at the end of study period depicted that maximum response in the form of score was given by 20 judges for flavor of preserved mushrooms ranged between 7.36 - 7.40, when, $0.075 \%$ KMS and $0.075 \% \mathrm{SB}$ were used for preservation of mushrooms. When the original values computed $(0.073$ and $0.071,0.074$ and 0.074 , and 0.071 and 0.068 for KMS and SB, respectively) against the central point of the contours were fitted in the equation (Figure 4-6), a value of 7.50 for A. bisporus, A. bitorquis and P. ostreatus were obtained which reflected the optimum levels of score for flavor obtained as a result of combination of chemical preservatives. The signs of the regression coefficients within each equation show the direction of the effect of each independent variable, the squares and the interaction. Considering such information together with the $\mathrm{F}$ values (Table 5) provided insight. The regression analyses of data on sensory evaluation based on score assigned by judges for flavor of A. bisporus, A. bitorquis and $P$. ostreatus show significant results for KMS. Results for SB in case of $P$. ostreatus were highly significant, significant for A. bisporus and nonsignificant for A. bitorquis. Similarly, X12 for all mushrooms showed highly significant results. Similarly, X22 had highly significant value for A. bisporus, and $P$. ostreatus and significant for A. bitorquis. However, interaction between $\mathrm{X} 1$ and $\mathrm{X} 2$ were non-significant.

Mean square values for regression analyses (Table 5) show highly significant values for all three mushrooms. The higher R2 values more than $50 \%$ and near to $100 \%,(89.2 \%)$ for A. bisporus, $(83.3 \%)$ for A. bitorquis and (87.9\%) for $P$. ostreatus indicate that the model fitted the data adequately and good fit of the models. The human nose can detect some odorous substances when approximately 10-19 moles of some volatiles are present in the nasal cavity [34]. The threshold value for 1-Octen-3-Ol in water is $0.001 \mathrm{mg} / \mathrm{Kg}$ [35]. It is a minor component of mushroom volatiles, but, has highest aroma value in fresh mushrooms [36].

It contributes significantly to the flavor of A. campestris and A. bisporus [37, 38 and 39]. This volatile flavor compound is formed enzymatically from linoleic acid [40], which was shown to be the major fatty acid in A. bisporus. Enzymes involved in the pathway formation of 1-Octen-3-O1 include lip oxygen hydro peroxide cleavage enzyme, and alcohol oxidoreductase [41]. Flavor represents a combination of sensations including taste, smell and touch. The interaction of tastes and odors complicate the sensory evaluation of food flavors [42]. Temperature influences the volatility of compounds that elicit aroma and odor. Hot and cold sensations contribute to the overall flavor of food. Little work has been done on sensory properties of the compounds identified in mushrooms. Most of the flavor compounds do not exist in fresh mushrooms but are formed during cooking. Volatiles produced by cooking are usually resulted from the breakdown of the main components of mushroom, e.g., carbohydrates, protein, and lipids [43]. Ajay and Saini conducted studies on extension of shelf-life of $A$. bisporus $\mathrm{L}$. mushrooms by using chemical preservatives in steeping solutions.
The treatment containing acetic acid $(0.5 \%)+$ sodium benzoate $(0.05 \%)+$ potassium meta bi sulphite $(0.05 \%)+$ common salt $(5 \%)$ showed best results for keeping mushrooms in an acceptable condition during storage for a period of 3 months. However, blanched samples had good flavor as compared to unblanched mushrooms [30]. Results of this study show that flavor for mushroom varieties is highly significantly different, which means that all the mushrooms have variable quantity of flavor. In case of A. bitorquis mushroom variety, highest mean value for flavor was found, which showed that this mushroom has more enzyme which might be converted to certain flavor compounds and other degradable products. Considering the results of absorbance of the same mushroom variety (not presented in this paper) had more mean values for it also confirms that this mushroom is much superior in terms of genetic capabilities to degrade organic waste material into food material [48]. However, addition of appropriate amounts of KMS just enough to produce the desired effect helped to retain maximum flavor in mushrooms preserved with chemical methods [43]. RSM was much more helpful in optimization of dozens of chemical preservatives in a way that flavor was not much affected by the dozens of chemical pre-servatives. The actual chemical dozes were higher $(0.075)$ which were reduced to 0.073 for KMS and 0.071 for SB in case of A. bisporus mushroom. Similarly, actual values were also reduced to $0.074,0.071$ for KMS and $0.074,0.68$ for SB in case of A. bitorquis and P. ostreatus mushrooms, respectively.

\section{Taste}

The contour diagrams (Figure 7-9) show maximum responses for taste at optimum levels of chemical preservatives KMS and SB for preservation of $A$. bisporus, A. bitorquis and P. ostreatus mushrooms. The contours of taste of mushrooms at the end of study period depicted (Figure 7 - 9) that maximum response in the form of score given by judges for taste of preserved mushrooms ranged between 7.11 - 7.36, when, $0.075 \%$ KMS and $0.075 \% \mathrm{SB}$ were used for preservation of mushrooms. When the original values computed (0.070 and $0.067,0.073$ and 0.069 , and 0.070 and 0.068 for KMS and SB, respectively) against the central point of the contours were fitted in the equation, a value of 7.15 for A. bisporus, 7.40 for A. bitorquis and P. ostreatus were obtained, which reflected the optimum levels of score for taste acquired as a result of combination of chemical preservatives.

The signs of the regression coefficients within each equation show the direction of the effect of each independent variable, the squares and the interaction. Considering such information together with the F-values (Table 6) provided insight. The regression analyses of data on sensory evaluation based on score assigned by judges for taste of A. bisporus, and P. ostreatus mushrooms show significant results for KMS and SB.

Table 6. Regression analyses for taste of different mushrooms

\begin{tabular}{|c|c|c|c|c|}
\hline \multirow{2}{*}{\multicolumn{2}{|c|}{ Parameter }} & \multicolumn{3}{|c|}{ Regression coefficients } \\
\hline & & A. bisoporus & A. bitorquis & P. ostreatus \\
\hline \multicolumn{2}{|c|}{ Constant } & 1.754 & -2.585 & -4.723 \\
\hline \multicolumn{2}{|c|}{$\mathrm{X}_{1}(\mathrm{KMS} \%)$} & $85.50 *$ & $168.60 * *$ & $169.56 *$ \\
\hline \multicolumn{2}{|c|}{$\mathrm{X}_{2}(\mathrm{SB} \%)$} & $71.75 *$ & $108.60 *$ & $181.23 *$ \\
\hline \multicolumn{2}{|c|}{$\mathrm{X}_{1}^{2}$} & $-729.8 * *$ & $-1025.7 * *$ & $-1014.7 * *$ \\
\hline \multicolumn{2}{|c|}{$\mathrm{X}_{1} \times \mathrm{X}_{2}$} & $250.0^{\mathrm{NS}}$ & $-250.0^{\mathrm{NS}}$ & $-375.0^{\mathrm{NS}}$ \\
\hline \multicolumn{2}{|c|}{$\mathrm{X}_{2}^{2}$} & $-667.3 * *$ & $-650.7 *$ & $-1139.7 * *$ \\
\hline \multicolumn{2}{|c|}{$\mathrm{R}^{2}(\%)$} & 86.2 & 82.7 & 74.5 \\
\hline Source & Degree of freedom & \multicolumn{3}{|c|}{ Mean squares } \\
\hline $\begin{array}{l}\text { Regression } \\
\text { Error }\end{array}$ & $\begin{array}{l}5 \\
8\end{array}$ & $\begin{array}{c}0.0429 * * \\
0.0043\end{array}$ & $\begin{array}{c}0.0731 * * \\
0.0096\end{array}$ & $\begin{array}{c}0.0972 * \\
0.0208\end{array}$ \\
\hline
\end{tabular}




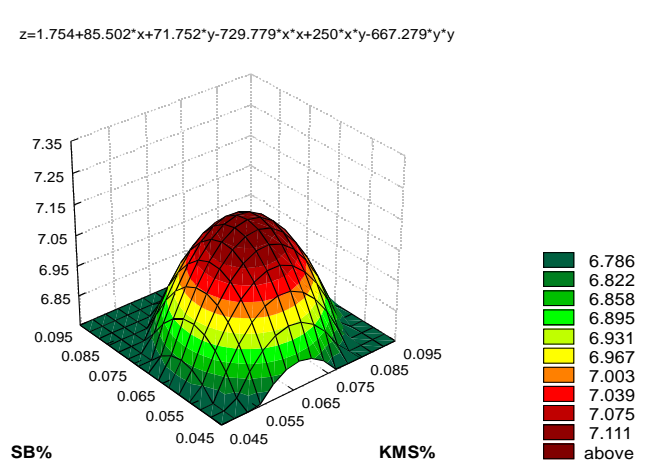

Figure 7. Contour plot showing the effect of KMS\% and SB\% on taste of (Agaricus bisporus) mushroom

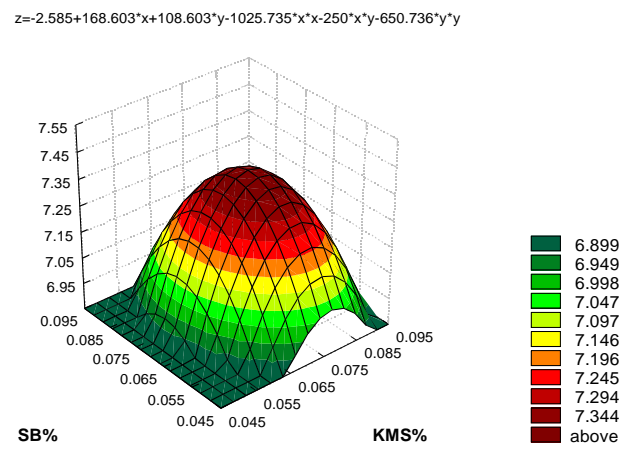

Figure 8. Contour plot showing the effect of KMS\% and SB\% on taste of (Agaricus bitorquis) mushroom

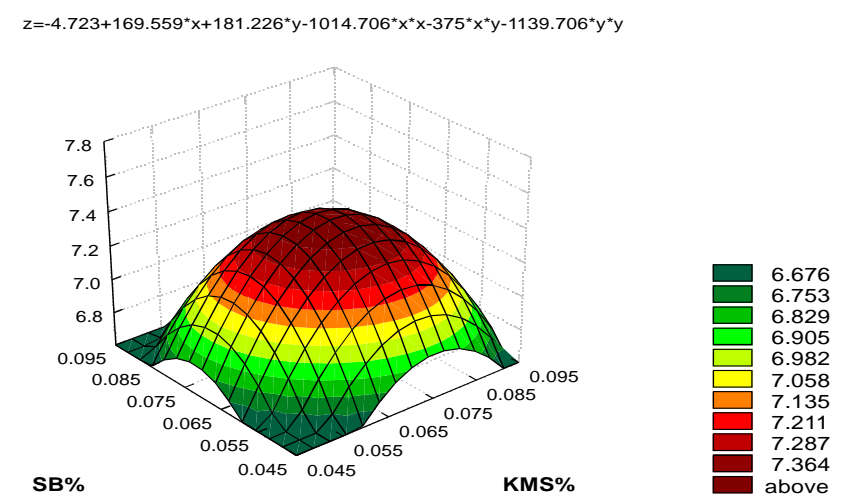

Figure 9. Contour plot showing the effect of KMS\% and SB\% on taste of (Pleurotus oystreatus) mushroom

While highly significant results were observed in case of A. bitorquis mushroom for KMS. Similarly results for X12 showed highly significant values for all mushrooms. The X22 value for A. bitorquis showed significant value. However, interaction between $\mathrm{X} 1$ and $\mathrm{X} 2$ was non-significant for all mushrooms. Mean square values for regression analyses (Table 6) showed highly significant values for A. bisporus, and A. bitorquis, while it was significant for P. ostreatus mushroom. The higher R2 values more than $50 \%$ and near to $100 \%$ reflects good fit of the model, (86.2\%) for A. bisporus, $(82.7 \%)$ for A. bitorquis and (74.5\%) values for $P$. ostreatus indicate that the model fitted the data adequately and good fit of the models. The sensory score for taste ranged from 7.15 to 7.40 as assigned by a panel of judges. Minimum score (7.15) for taste was observed in A. bisporus, while, other two mushrooms (A. bitorquis and P. ostreatus) obtained an equal maximum score (7.40).

Taste thresholds may vary greatly among individuals. There is no objective method for evaluation of taste, which is the most important of all criteria [44]. Some scientists found that taste threshold of a group of 25 preschool children were found to be similar to the adults [45]. However, some scientists show discrimination in taste was observed among old age groups (80 - 85 years) as well as did a control group of 40 - 45 years of age [46].

\section{CONCLUSION}

Scientific studies are mainly aimed at to keep the original color of the mushrooms during the period of post-harvest handling, processing and distribution. The color changes from white to brown are also evident during prolonged storage due to the activities of polyphenol oxidase (PPO), and monophenol mono-oxidase (tyrosinase) enzymes. Browning reactions become evident when mushrooms are subjected to processing. In present studies, mushrooms were selected at the same phase of maturity from same flushes because, mushrooms from successive flushes become progressively darker prior to harvesting and browning occurs at a faster rate during post-harvest storage. The browning tendency between breaks is also affected by differences in composition, susceptibility to injury due to environmental conditions or crop density, and extraction of PPO from mushroom surface during washing.

The mushrooms were blanched in boiling water in order to inactivate the enzyme system and to expel the air from the cell of the mushrooms because most important factors that determine the rate of enzymatic browning in mushrooms are the concentration of active $\mathrm{PPO}$ and phenolic compounds present, the $\mathrm{pH}$, the temperature and the oxygen availability to the tissue. L-ascorbic acid was used in processing of mushrooms as an oxygen scavenger. The temperature stability of PPO varies with species and cultivars. The enzyme is relatively heat labile and activity is completely destroyed at $80{ }^{\circ} \mathrm{C}$. These results corroborate with the findings of scientists, who stated that use of $0.05 \%$ and $0.2 \% \mathrm{KMS}$ significantly improved the whiteness of mushrooms during storage. 


\section{CONFLICT OF INTEREST}

The authors declare no conflict of interest.

\section{REFERENCES}

[1] Chang ST, Miles PG, (2004) Mushrooms-Cultivation Nutritional Value Medicinal effect and Environmental Impact. (2th edtn), CRC Press, London pp 27- 37. (Crossref)

[2] Elsayed AE, Hesham EE, Mohammad AMW and Ramlan A, et al. (2014) Mushrooms A Potential Natural Source of Anti-Inflammatory Compounds for Medical Applications. Mediators of Inflammation. Article ID 805841, 15 pages. (

[3] Sarfraz, H, Raza, Q, Zahra, SM, Fatima, I, and Rashid, F, et al. (2017) Effect of Blood Group Diet on Infertility in ABO Blood Groups. J of Food and Dairy Tech. 5 (2): 38-41.

[4] Jurg L, (2000) Function and importance of glutamate for savory foods. J of Nutrition. 130 (4): 915-920.

[5] Santford VO, Manura JJ, (2003) Determination of Volatile organic compounds in mushrooms. Available on (AP Note 18 - Determination of Organics in Mushrooms). Scientific Instrument services Inc., 1027 Old York Road, Ringoes, NJ 08551 WEB: http://www.sisweb.com/

[6] Sandhu KS, and Aggarwal P, (2001) Steeping preservation of mushrooms (A. bisporus). J Res Punjab Agric University. 9 (1): 13-15.

[7] Box GEP, and Draper NR, (1987) Empirical model building and response surfaces. John Weley, New York, USA.

[8] Wadikar DD, Majumdar TK, Nanjappa C, Premavalli KS, and Bawa AS, et al. (2008) Development of shelf life stable pepper-based appetizer b response surface methodology (RSM). LWT 41: 1400-1411. (Crossref)

[9] Martens M, (1986) Sensory and Chemical physical quality criteria of frozen peas studied by multivariate data analysis. J Food Sci. 51 (3): 599603. (

[10] Colin D, and Lucas J, (1979) The Encyclopedia of Mushrooms G.P. Putnam's Sons, New York. pp 89-111.

[11] Bennett H, (1951) The Chemical Formulary Chemical Publishing Co. Inc. New York 11: 226.

[12] Montgomery DC, (2001) Design and Analysis of Experiments (5th edtn), John Wiley \& Sons, Inc, New York pp. 427-510.

[13] Minitab, (1996) Release 11.12-32 bit Minitab, Inc., 814-238-3280. Enterprise Drive State College, PA 16108-3008, USA.

[14] Czarnecki J, (1986) Brining mushrooms. Joe's Book of Mushroom Cookery. A Simon \& Schuster Macmillan Company, 1633 Broadway New York pp 312-313.

[15] Land DG, and Shepherd R, (1988) Scaling and Ranking Methods. In: Sensory Analysis of Foods. Piggott, J. R. (Ed). Elsevier Applied Sci., New York pp 155-85.
[16] Gacula Jr. MC, and Singh J, (1984) Statistical Methods in Food and Consumer Research. Academic Press Inc. Orlando Florida pp 489.

[17] Steel RGD, Dickey D, and Torrie JH, et al., (1996) Principles and procedures of statistics - a biomaterial approach. (3th edtn), McGraw Hill Book Co. Inc. London.

[18] Mitcham B, Marita C, and Adel K, et al., (1996). Methods for determining quality of fresh commodities. Perishables Handling Newsletter, Issue No. 85: $1-5$.

[19] Majid HA, (1993) Studies on dehydration of oyster mushrooms. M.Sc. Thesis, Department of Food Technology, University of Agriculture Faisalabad.

[20] Goodenough PW, (1976) How chilled storage affects the physiology of mushrooms. Mush J. 43: 208-210.

[21] Xiong Li, (2000) Extend shelf life of mushroom by using micro-perforated film - a research proposal. Department of Food Science, Pennsylvania State University.

[22] Whitaker JR, and Lee CY, (1995) Recent advances in chemistry of enzymatic browning. In: Enzymatic browning and its prevention. Lee, C. Y. and J. R. Whitaker (ends), ACS Symposium Series 600. Washington DC, USA pp 2-7. (Crossref)

[23] Bartley CE, Beelman RB, and Winnett JR, (1991) Factors affecting color of cultivated mushrooms (A. bisporus) prior to harvest and during postharvest storage. Mush Sci. 13 (2): 689-94.

[24] Gerald MS, Robert LM, Fredrick CM, Peter HC, and Sang-won C, et al., (1994) Enzymatic browning control in minimally processed mushrooms. J Food Sci. 59 (5): 1042-47. (Crossref)

[25] Bauernfeind JC, Ascorbic acid: chemistry, metabolism and uses. In: Adv. Chem. Res. Seib PA, Tolbert BM, (1982) American Chemical Society, Washington, DC pp 395-476.

[26] Newsome RL, (1987) Use of vitamins as additives in processed foods. Food Technol 9: 163-68.

[27] Vamos-Vigyazo L, (1981) Polyphenoloxidase and peroxidase in fruits and vegetables. CRC Crit Rev Food Sci Nutr. 15 (1): 49-12. (Crossref)

[28] Bhatia BS, and Mudahar GS, (1982) Preparation and storage studies on some intermediate moisture vegetables. J Food Sci and Technol 19 (2): 4043.

[29] Richard M. H, (2007) The taste of Mushrooms. Mcllvainea. 17 (1): 33-41.

[30] Ajay S, and Saini LC, (1995) Post-harvest technology of white button mushroom. Haryana J Horti Sci. 24 (1): 97-102.

[31] Saxena S, and Rai RD, (1988) Storage of button mushrooms (Agaricus bisporus): the effect of temperature, perforation of packs and pre-treatment with potassium metabisulfite. Mush J Tropics. 8 (1): 15-22.

[32] Moncrieff RW, (1980) Sensory Characteristics of Food Quality. In: The Science of Food. Bennion, M. (2th edtn), John Wiley \& Sons New York pp $3-4$. 
[33] Fennema OR, (1976) Principles of Food Science - Food Chemistry Part I. Marcel Deker Inc. New York pp 428-461.

[34] Teranishi R, Issenberg P, Hornstein I, and Wick EL, et al. (1971) Flavor Research. Marcel Dekker Inc, New York (1971).

[35] Hamilton D, (2003) Off-flavors in foods. Available: http://www.britanniafood.com/common/invite_17.htm pp1-8

[36] Fischer KH, and Grosch W, (1987) Volatile compounds of importance in the aroma of mushrooms (Psalliota bispora). Lebensmittel-Wissenschoft Und-Technol. 20 (1): 233-36.

[37] Tressl R, Daoud B, and Engel KH, (1982) Formation of eight-carbon and ten-carbon compounds in mushrooms (A. campestris). J Agri Food Chem. 30 (2): 89-93. (Crossref)

[38] Wurzenberger M, and Grosch W, (1982) The enzymic oxidative breakdown of linoleic acid in mushrooms (Psalliota bispora). Z Lebensm Unters Forsch. 175 (1): 186-190. (

[39] Chen CC, and Wu CM, (1984) Studies on the enzymatic reduction of 1octane-3-one in mushroom (A. bisporus). J Food Agri. 32: 1342-44.

[40] Morawicki RO, Beelman RB, and Peterson D, et al. (2002) Simultaneous analysis of 1-octen-3ol and 10-oxo-trans-8-decenoin acid in mushrooms using gas chromatography. Available from 15C-23 Simultaneous analysis of 1-Octen-3-Ol and 10-Oxo-trans-8-decenoic acid in mushroom. Department of Food Science, the Pennsylvania State University, 20 Borland Lab. University Park, PA 16802. Session 15C, Food Chemistry: Food composition and analysis. Annual Meeting and Food Expo-Anaheim, June 16th, 2002. California.

[41] EVA Medved, (1986) Food - Preparation and Theory. Prentice Hall, Inc. Englewood Cliffs, New Jersey 07632.

[42] Srivastava RP, and Sanjeev K, (2003) Fruit and Vegetable Preservation Principles and Practices. (3th edtn), International Book Distributing Co. Chaman Studio Building, U. P. India. pp 93-96, 300-302.

[43] Chang ST, and Miles PG, (1989) Edible Mushrooms and Their Cultivation. CRC Press, Inc. Boca Rotan, Florida pp 27-38, 270-271.

[44] Girdhari L, Siddappa GS, and Tandon GL, (1998) Preservation of fruits and vegetables. Indian council of Agricultural Research, publication and information division, New Delhi 110012. pp 73-74.
[45] Korslund MK, and Eppright ES, (1967) Taste sensitivity and eating behavior of pre-school children. J Home Economics. 59 (1): 169.

[46] Kare MR, (1975) Changes in taste with age- infancy to senescence. Food Technol. 29 (1): 78.

[47] Ahmad, (1990) Performance of different species of Pleurotus (Oyster mushrooms) on various agricultural and Industrial waste materials. M.Sc. Thesis. Department Horticulture, University of Agriculture, Faisalabad, Pakistan. pp 1-92.

[48] Preeti S, Horst-Christian L, Ali AW and Sven S, et al., (2010) Recent advances in extending the shelf life of fresh Agaricus mushrooms: A Review. Published online in Wiley inter science: J Sci Food Agric. 90: 1393-1402. (Crossref)

\section{How to Cited this article?}

Hussain S, Rehman S, Raza Q, Fatima I, Zahra SM, et al. Optimization of sensory properties of chemically preserved Mushrooms through response surface methodology. 2017; 1 (1): 006-014 